\title{
KAJI EKSPERIMETAL PENGHAMBAT PENJALARAN RETAK DENGAN MENGGUNAKAN PENGAKU
}

\author{
Hendery Dahlan, Yudi Dwianda, Meifal Rusli \\ Jurusan Teknik Mesin, Fakultas Teknik, Universitas Andalas \\ Kampus Limau Manis, Padang, Sumatera Barat \\ Email: henderydahlan@ft.unand.ac.id
}

\begin{abstract}
ABSTRAK
Salah satu penyebab retak muncul di struktur biasanya berawal pada daerah yang mengalami konsentrasi tegangan yang tinggi. Jika pembebanan terus dilakukan maka retak akan terus tumbuh dan menjalar sehingga menyebabkan terjadinya kegagalan. Oleh karena itu, diperlukan suatu cara atau metode yang efektif untuk menahan laju pertumbuhan retak sebelum kegagalan terjadi. Pada penelitian ini akan dilakukan kajian secara eksperimental pengaruh lasan, dimensi pengaku dan jumlah pengaku terhadap beban kritis sebelum retak menjalar. Dari penelitian yang telah dilakukan dapat disimpulkan bahwa pengaku yang diberikan sangat efektif mempengaruhi laju perambatan retak. Selain itu, dimensi pengaku mempengaruhi penghambatan penjalaran retak dimana semakin besar dimensi pengaku maka rata rata beban kritis yang dibutuhkan untuk retak mulai menjalar semakin besar. Sementara itu kualitaspengelasan pada retak sangat mempengaruhi penghambatan retak untuk menjalar.
\end{abstract}

Kata Kunci: Retak, Pengaku, Penghambat Retak, Beban Kritis.

\begin{abstract}
One of the causes of cracks appearing in structures usually begins in areas having high stress concentrations. If loading continues to be subjected, then the crack will continue to grow and propagate so that it causes failure. Therefore, an effective method is needed to restrain the crack growth rate before failure occurs. This research will be conducted an experimental study of the influence of welds, dimensions of the stiffener and the number of stiffener relating to the critical load before crack propagation. It can be concluded that the stiffener given significantly affect in crack propagation rate retardation.In addition, the stiffener dimension affects the inhibition of crack propagation where the greater the dimension of the stiffener, the average critical load required for crackgrowthwill increase. Meanwhile, the quality of welding on cracks greatly affects the inhibition of crack propagation.
\end{abstract}

Keywords: crack, stiffener, crack arrest, critical load.

\section{PENDAHULUAN}

Banyak kegagalan komponen mesin atau struktur di lapangan disebabkan oleh sebuah retak. Retak ini dapat disebabkan oleh cacat pada proses pembuatan, daerah-daerah yang memiliki konsentrasi tegangan yang tinggi akibat dari bentuk geometri sehingga pada saat komponen mesin atau struktur beroperasi (in service) dapat menyebabkan retak muncul. 
Komponen mesin atau struktur yang memiliki retak akan mengalami pengurangan kekuatan pada saat beroperasi. Oleh karena itu jika pada komponen mesin atau struktur tersebut memiliki retak, maka perlu dilakukan proses penggantian komponen tersebut tetapi sebelum dilakukan penggantian komponen tersebut perlu dilakukan pencegahan agar retak tersebut tidak menjalar yang nantinya akan menyebabkan kerusakan pada komponen mesin atau struktur sehingga proses produksi dapat terganggu atau bahkan terhenti.

Perkembangan penelitian tentang rambatan retak, mengalami kemajuan yang signifikan. Salah satu penelitian tentang penghambat pertumbuhan retak dilakukan oleh Murdani dan kawan-kawan [1]. Murdani mengemukakan sebuah teknik baru untuk menahan laju perambatan retak pada stop-drilled holes (SDH) dengan membuat beberapa lubang di sekitar stop hole pada bahan alluminium alloy. Hasil perhitungan memperlihatkan bahwa adanya lubang di sekitar stop holes mengurangi konsentrasi tegangan. Jarak dan besar lubang juga mempengaruhi besarnya pengurangan konsentrasi tegangan disudut stop holes [1].

Penelitian lain tentang metode teknis untuk menghambat pertumbuhan retak lebih lanjut adalah dengan menggunakan lubang yang dibuat di sekitar ujung retakan (the crack tips) [2]. Pada sebagian lubang tersebut dimasukkan pin. Ditemukan bahwa lubang dan pin yang dimasukkan tersebut dapat memperpanjang waktu pertumbuhan retak. Lubang dan pin juga dapat mengubah arah pejalaran retak sehingga dapat mencegah bertemunya retak. Ditemukan juga bahwa tegangan sisa kompresif yang timbul akibat dimasukkannya pin lebih efektif mengambat pertumbuhan retak dari pada mengurangi konsentrasi tegangan disekeliling ujung retakan dengan cara membuat lubang [2].

Walaupun cukup banyak studi tentang jenis-jenis perbaikan yang dapat dilakukan terhadap retakan seperti yang diulas oleh Mazarni et.al. [3], namun tidak semua cara dapat dilakukan pada setiap kasus. Efektifitas dari jenis perbaikan terhadap retakan perlu diperhatikan,seperti yang didiskusikan Macabe pada risetnya [4].

Pada aplikasi di lapangan, tambalan (patches) dapat digunakan untuk memperbaiki bagian pesawat dan jembatan. Namun pada daerah kerja yang sempit metode ini atau metode lain seperti penjahitan (stitching) tidak efektif digunakan. Pada kondisi seperti ini Macabe mengusulkan penggunaan metode lubang-hambat (stop-hole) dan pengaku (arrester), akan tetapi penggunaan lubang-hambat saja tanpa memasukkan pin atau baut tidak efektif untuk menghambat penjalaran retak. Sementara itu jika pengaku digunakan, jumlah stress cycles terhadap timbulnya retak dan penjalaran retak dapat meningkat dibandingkan dengan tanpa pengaku [4].

Metode yang paling umum yang digunakan untuk mencegah pertumbuhan retak adalah dengan membuat lubang hambat di ujung retak [5]. Dengan metode ini konsentrasi tegangan di ujung retak menjadi berkurang. Dua-parameter mekanika retak (two-parameter fracture mekanics)diusulkan sebagai sebuah indeks yaituDRI(DrillingRepairIndex), untukmengevaluasi efisiensi dari metode lubang-hambat (stop hole) [5]. Selain itu, kriteria dua-parameter mekanika retak telah dikemukakan untuk memprediksi kondisi retakan pada komponen. Kriteria ini terdiri dari faktor intensitas tegangan kritis takik, $\mathrm{K}_{\rho, \mathrm{c}}$ yang menggambarkan ketangguhan retak (fracture toughness) dari material dan efektif T-stress. Efektif T-stress, $\mathrm{T}_{\mathrm{ef}}$, merupakan nilai rata-rata dari distribusi tegangan di sekitar takikan [11].

Metode lubang-hambat dan pengaku ini juga pernah diuji penerapannya pada komponen dengan pengelasan [6]. Metode tersebut digunakan karena metode perbaikan dengan pengelasan kurang efektif digunakan karena metode ini menimbulkan tegangan sisa (residual stress). Pada penelitian tersebut disimpulkan bahwa fatigue life akan bertambah jika pengaku dipasang pada bagian flat dari komponen yang berlawanan dengan posisi lasan. Ketika daerah yang bersentuhan dari pengaku dengan permukaan komponen lebih lebar dan perpindahan retak (crack displacement) dibuat lebih kecil maka fatigue life akan lebih panjang [6]. 
Proses penghambatan retak sangat tergantung pada kasus-kasus retakan yang terjadi pada komponen komponen mesin dan struktur. Tidak semua metodologi penghambatan retak dapat digunakan untuk semua kasus yang terjadi. Untuk keretakan yang terjadi pada pipa yang didalamnya ada tekanan tinggi atau ada fluida yang mengalir, proses penghambatan retak dengan membuat lubang pada ujung retak tidak efektif digunakan. Pada saat ini prosedur yang sering dilakukan di lapangan adalah dengan melakukan proses pengelasan pada daerah retakan, tetapi proses ini tidak memberikan solusi yang efektif karena jika proses pengelasan dilakukan tidak degan baik maka retak akan terjadi kembali di daerah yang sama. Oleh sebab itu perlu dilakukan mekanisme tambahan untuk mencegah retak terjadi kembali, yaitu dengan memberikan pengaku pada daerah retakan yang sudah dilas. Penahan atau pengaku mempunyai fungsi untuk mengurangi konsentrasi tegangan pada ujung retak sehingga dapat menghambat penjalaran retak sehingga retak yang terjadi tidak meluas dan merusak struktur. Untuk permasalahan ini dilakukan pengujian dengan menggunakan spesimen uji yang dibuat dari bahan baja pelat hitam, steel plate mild ASTM A36.

Secara umum retak mulai menjalar jika beban yang diberikan telah mencapai beban kritis yang mampu di tahan oleh sebuah struktur, oleh karena itu tujuan yang hendak dicapai pada penelitian ini adalah mencari model penghambatan penjalaran retak dari tiga variasi model dengan mempertimbangan nilai pembebanan kritis dari esperimen yang dilakukan.

Dalam penelitian ini permasalahan dibatasi sebagai berikut:

1. Diasumsikan keretakan yang terjadi hanya dengan modus I (Openingmode) dengan pengujian yang dilakukan adalah uji tarik.

2. Material pengaku sama dengan material spesimen yaitu baja pelat hitam, steel plate mild ASTM A36.

3. Pengelasan dilakukan dengan metode pengelasan SMAW menggunakan listrik arus DC dengan elektroda RD 260

\section{METODE PENELITIAN}

\section{Perancangan Spesimen Uji}

Bahan spesimen uji adalah pelat logam dengan tembal $3 \mathrm{~mm}$. Pelat ini dibentuk menjadi spesimen dengan ukuran 50 × $200 \mathrm{~mm}$. Ukuran ini diambil dengan referensi dari studi literatur yang telah dilakukan. Spesimen tersebutdiberi retakan awal (celah) dengan panjang $25 \mathrm{~mm}$ seperti yang terlihat pada gambar 1(a). Dalam rancangan spesimen uji ini,pengaku (crack arrester) dibuat dari logam yang sama dengan spesimen dengan ukuran 100x10 mm dan 100x20 mm yang disebut secara berurutan Pengaku-A dan Pengaku-B. Direncanakan pengaku-pengaku ini dipasang pada spesimen menggunakan las seperti yang terlihat pada gambar 1(b) dan 1(c). 

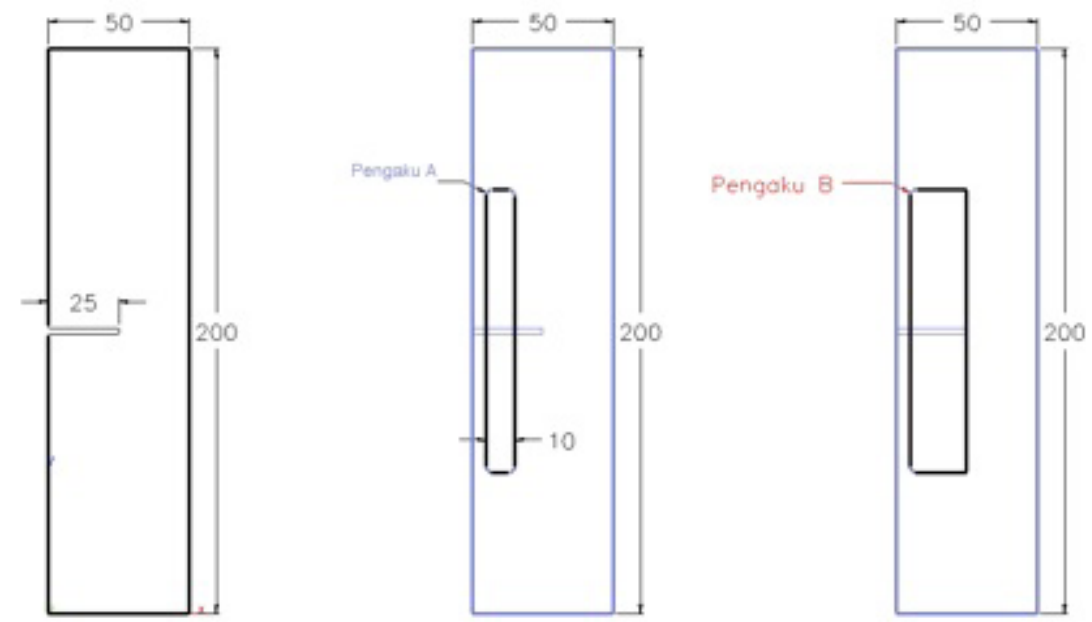

(a) (b) (c)

Gambar 1Rancangan spesimen uji, (a) tanpa pengaku,

(b) dengan pengaku-A (c) dengan pengaku-B

Ada empat jenis spesimen yang dipersiapkan yaitu:

\section{Spesimen A}

Spesimen A adalah spesimen dengan retak awal tanpa lasan. Spesimen ini dibuat dari pelat dasar dengan hanya ditambah proses pembuatan 'gauge length' dengan menggunakan gerinda seperti diperlihatkan pada gambar 2 .

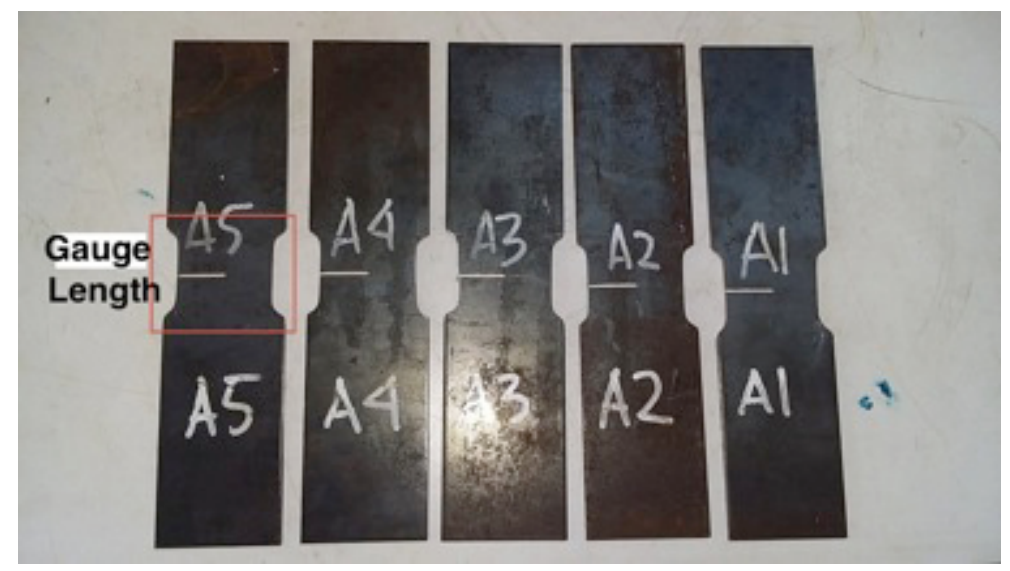

Gambar 2 Spesimen A dengan 'gauge length'

Gauge length adalah pengecilan penampang yang biasa ada pada spesimen standar. Kegunaan dari daerah gaugelength ini adalah untuk memastikan agar kerusakan (failure) breakage) yang terjadi pada saat pengujian tarik berada pada daerah gaugelength ini. Jika spesimen tidak memiliki daerah gaugelength ini maka ada kemungkinan spesimen putus pada pencekam.

\section{Spesimen B}

Spesimen B adalah spesimen yang diberi retak awal kemudian retak tersebut diperbaiki dengan cara dilas. Pengelasan dilakukan dengan metoda pengelasan SMAW menggunakan 
mesin las listrik arus DC. Setelah selesai dilas, pelat spesimen digerinda agar permukaannya menjadi rata. Proses terakhir dari pembuatan spesimen B adalah membuat gauge length dengan menggunakan mesin gerinda yang hasilnya terlihat pada gambar 3 .

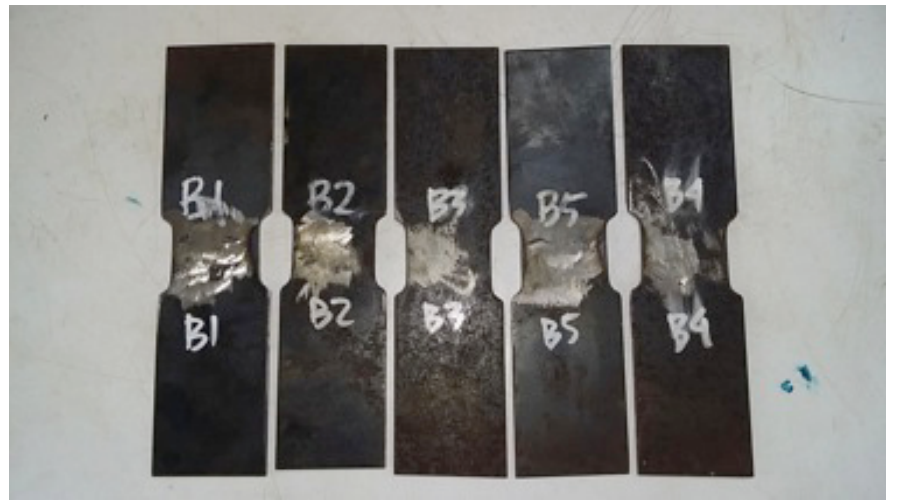

\section{Spesimen C}

Gambar 3 Spesimen B

Spesimen $\mathrm{C}$ adalah spesimen yang diberi retak awal kemudian retak tersebut dilas lalu diberi pengaku-A di satu sisi saja. Proses pembuatannya sama seperti proses pembuatan spesimen B kemudian ditambah dengan pemasangan pengaku yang mempunyai ukuran lebar $10 \mathrm{~mm}$ pada satu sisi menggunakan proses pengelasan SMAW. Hasilnya terlihat pada gambar 4.

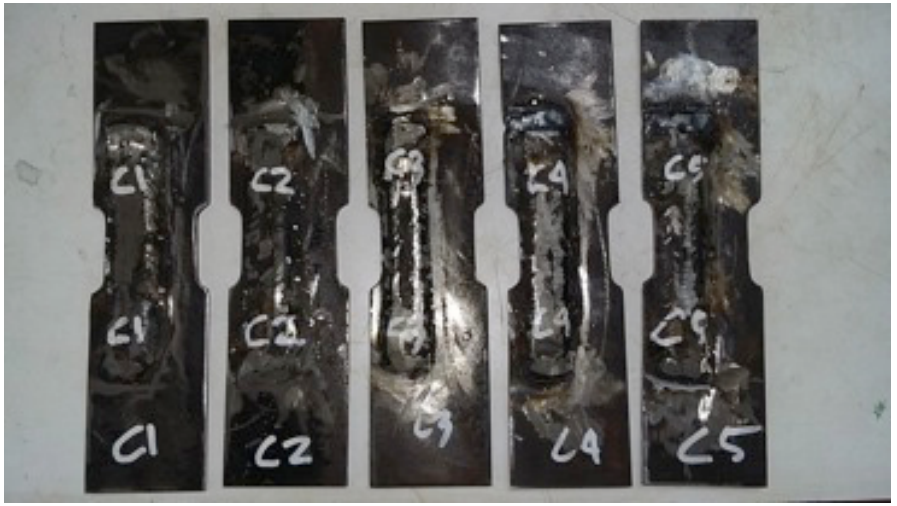

\section{Spesimen D}

Gambar 4 Spesimen C

Spesimen D adalah spesimen yang diberi retak awal kemudian retak tersebut dilas lalu diberi pengaku-B di satu sisi saja. Proses pembuatannya sama seperti proses pembuatan spesimen B kemudian ditambah dengan pemasangan pengaku yang ukuran lebar $20 \mathrm{~mm}$ pada satu sisi menggunakan proses pengelasan SMAW seperti yang terlihat pada gambar 5 . 


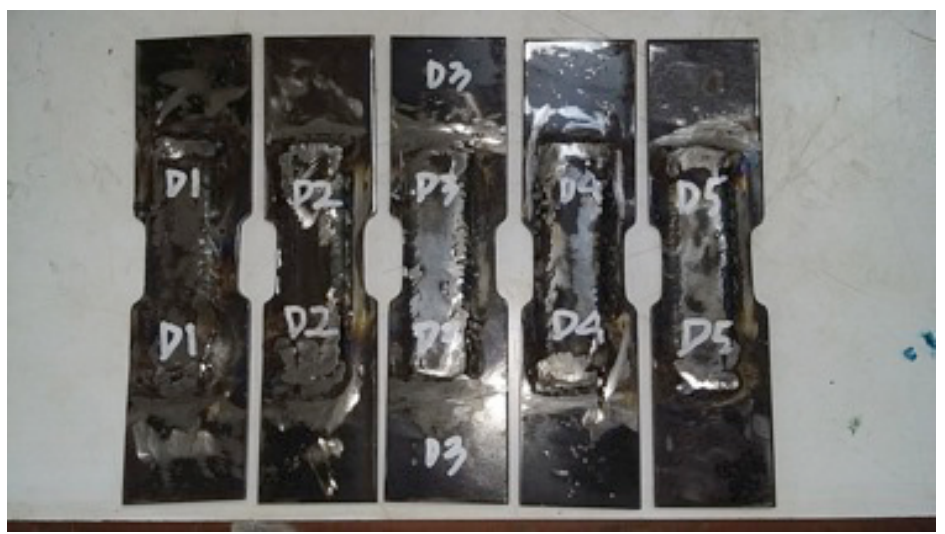

Gambar 5 Spesimen D

Spesimen D ini juga diberi gaugelength dengan cara digerinda.

Masing-masing perlakuan dibuat 5 buah spesimen sehingga total spesimen yang harus dipersiapkan adalah 20 buah.

\section{Pengujian}

Pengujian yang dilakukan adalah Pengujian Tarik yangdilakukan pada mesin uji tarik universal UTM, HungTa HT-8503 yang ada di Laboratorium seperti yang diperlihatkan gambar 6.

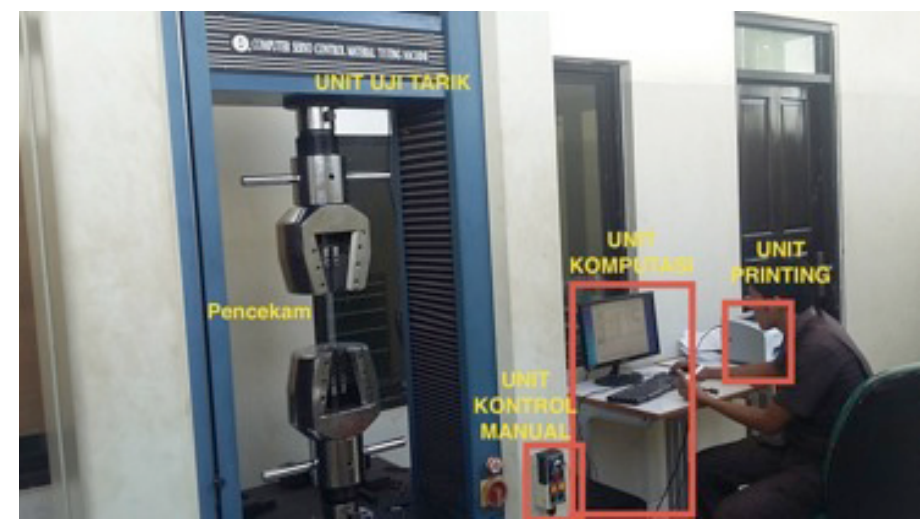

Gambar 6. Computer Servo Control Material Testing Machine

\section{HASIL DAN PEMBAHASAN}

Pengaruh penggunaan pengelasan dan pengaku untuk menahan pertumbuhan dan penjalaran retak dengan membandingkan nilai beban kritis yang diperoleh dari pengujian akan dibahas pada bagian ini. Sementara itu juga dibandingkan nilai beban kritis antara spesimen yang hanya memiliki retak awal dengan spesimen yang menggunakan retak awal kemudian diberi lasan. Adapun hasil pengujian spesimen dengan retak awal ini (Spesimen A) ditetapkan sebagai referensi. Selain itu pengaruh dimensi pengaku dan posisi pemasangan pengaku pada spesimen pengujian untuk menghambat laju pertumbuhan retak juga diperlihatkan.

Nilai beban kritis untuk lima buah specimen dari setiap empat macam jenis perlakuan pada retak diperlihatkan pada gambar 7 . 


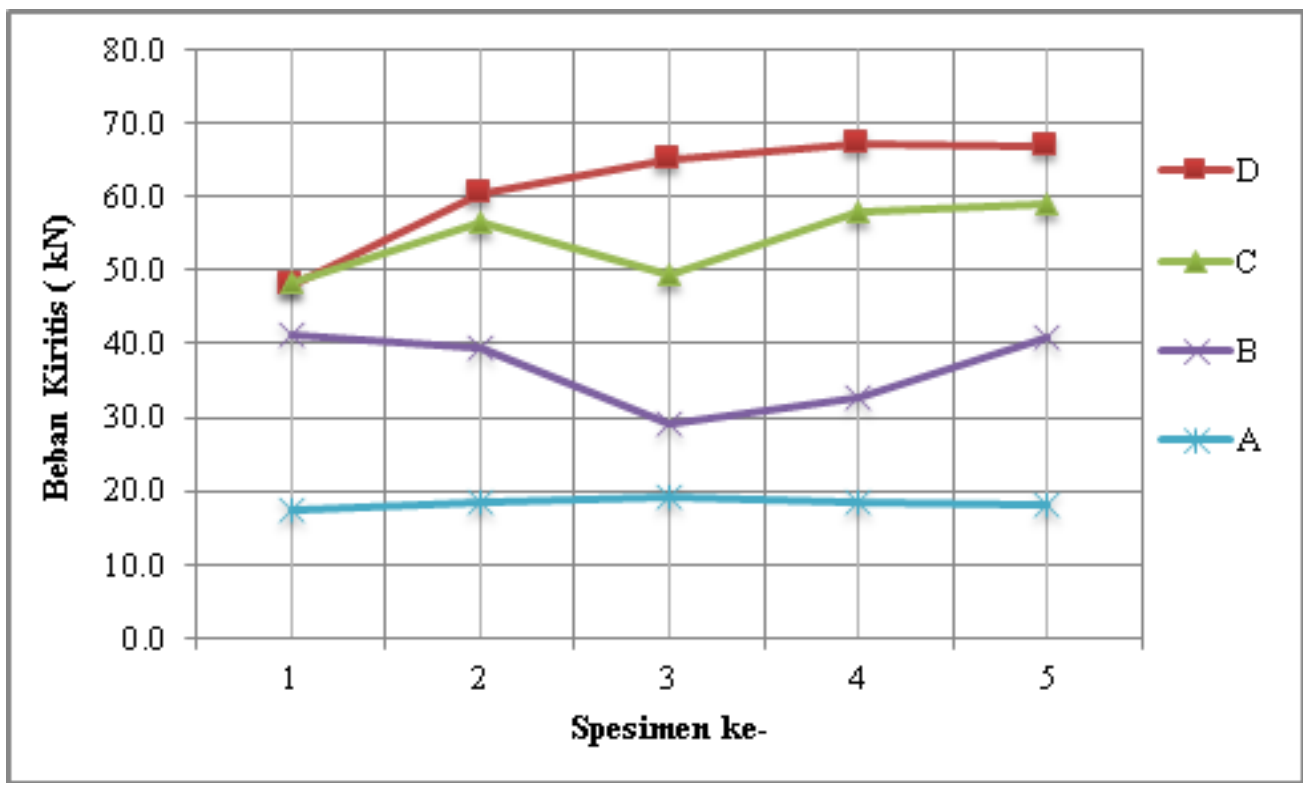

Gambar 7 Perbandingan nilai beban kritis Spesimen A, B, C dan D untuk lima buah spesimen

\section{Pengukuran Beban Kritis $\left(\mathbf{P}_{\mathrm{kritit}}\right)$ Pada Spesimen dengan Retakan yang dilas}

Pada gambar 7 terlihat bahwa secara umum nilai beban kritis spesimen B lebih tinggi dibandingkan dengan spesimen A. Akan tetapi nilai beban kritis Spesimen B3 (29kN) dan B4 $(32.83 \mathrm{kN})$ lebih rendah dibandingkan dengan spesimen B lainnya. Hal ini disebabkan oleh kualitas pengelasan yang kurang baik sehingga retakan muncul dan menjalar di daerah lasan seperti yang terlihat pada gambar 8 (a) dan (b). Namun nilai beban kritis Spesimen B3 dan B4 ini masih lebih tinggi dibandingkan dengan nilai beban kritis tertinggi spesimen tanpa lasan (Spesimen A).

Sementara itu padai gambar 8 (c) terlihat retakan spesimen B1 dimulai dan menjalar bukan pada daerah retakan awal yang sudah dilas. Pada spesimen ini kualitas lasan cukup baik sehingga retak muncul dan menjalar pada daerah kritis lain.

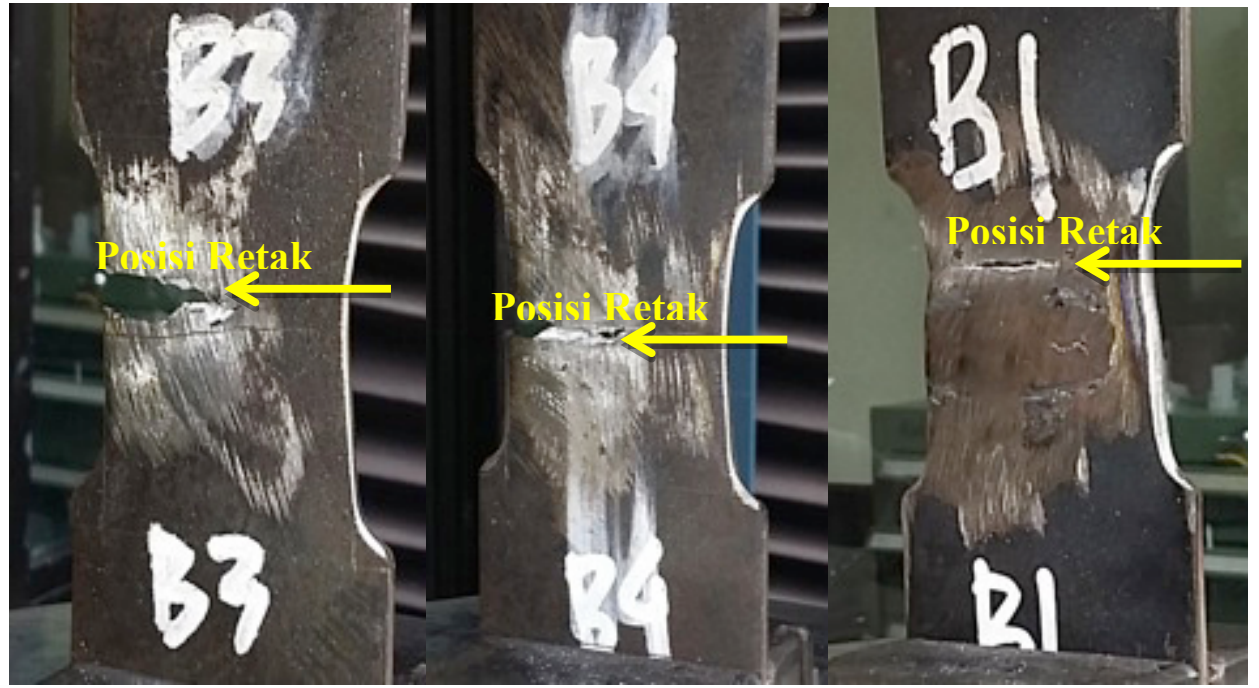

(a)

(b)

(c)

Gambar 8 Posisi penjalaran retak pada (a) Spesimen B3, (b) Spesimen B4 dan (c) Spesimen B1 


\section{Pengukuran Beban Kritis $\left(\mathrm{P}_{\text {kritis }}\right)$ Pada Spesimen dengan retakan yang dilas diperkuat dengan Pengaku Satu Sisi}

Pengaruh pengaku satu sisi dengan lebar $10 \mathrm{~mm}$ (Spesimen C) terhadap beban kritis diperlihatkan pada 7. Pada gambar terlihat bahwa nilai rata-rata beban kritis spesimen $\mathrm{C}$ lebih tinggi dibandingkan dengan spesimen B dan Spesimen A. Pada gambar 7 terlihat bahwa nilai beban kritis Spesimen C1 (48.5kN) lebih rendah dibandingkan dengan spesimen C lainnya. Hal ini disebabkan pengaku tidak ikut dicekam sehingga retakan muncul dan menjalar di daerah pencekaman seperti yang terlihat pada gambar 9 (a).Sementara untuk empat spesimen lainnya pengaku ikut di cekam dalam proses pengujian.

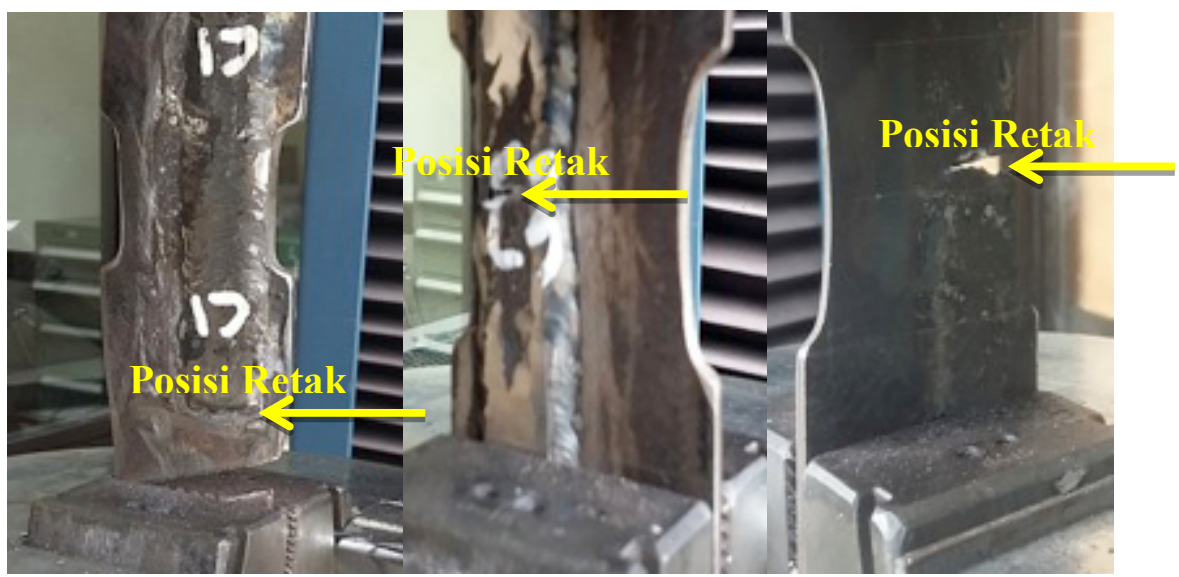

(a) (b) (c)

Gambar 9 Posisi penjalaran retak pada (a) Spesimen C1 (b) Spesimen C3 tampak depan dan (c) Spesimen C3 tampak belakang

Pada gambar 7 juga terlihat bahwa nilai beban kritis Spesimen C3 juga rendah mendekati nilai beban kritis spesimen $\mathrm{C} 1$. Hal ini dikarenakan proses pengelasan yang kurang baik sehingga penjalaran retak bermula dari daerah retakan awal yang diberikan seperti yang diperlihatkan gambar 9 (b) dan (c). Akan tetapi nilai beban kritis Spesimen C3 (49.26kN) masih lebih tinggi dibandingkan dengan nilai beban kritis Spesimen B3 $(29 \mathrm{kN})$ walaupun kedua spesimen tersebut gagal akibat lasan yang kurang baik. Hal ini disebabkan Spesimen C3 mempunyai pengaku yang menghambat penjalaran retak.

Pengaruh pengaku satu sisi dengn lebar $20 \mathrm{~mm}$ (Spesimen D) terhadap beban kritis diperlihatkan pada juga diperlihatkan pada gambar 7. Pada gambar terlihat bahwa nilai ratarata beban kritis spesimen D lebih tinggi dibandingkan dengan spesimen Cdan B

Pada gambar 7 terlihat bahwa nilai beban kritis D1 $(47.8 \mathrm{kN})$ hampir sama dengan $\mathrm{C} 1$ $(48.5 \mathrm{kN})$. Hal ini disebabkan oleh pengaku Spesimen D1 juga tidak ikut dijepit pada saat pengujian seperti yang terlihat pada gambar 10 . 


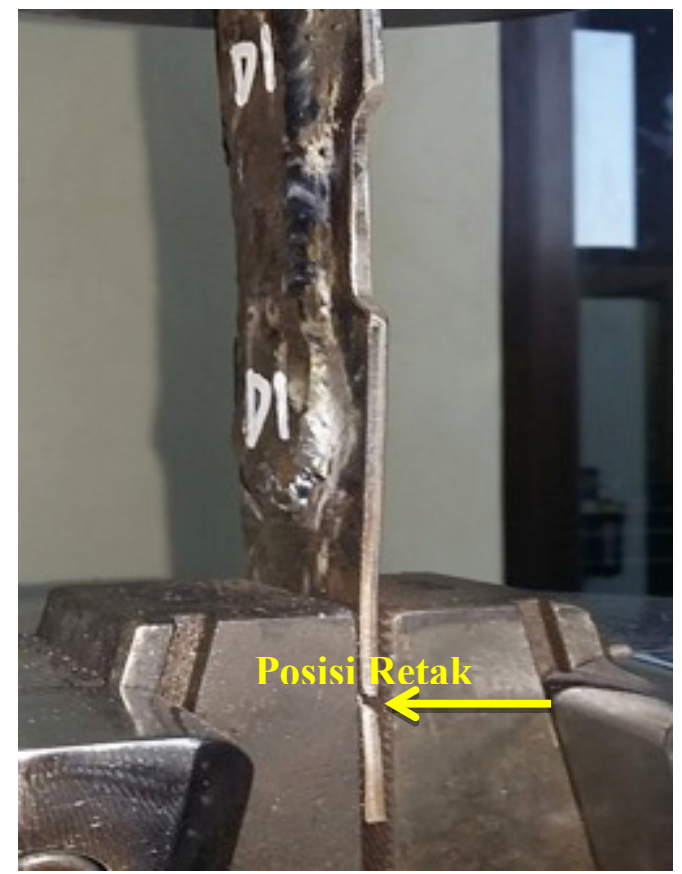

Gambar 10 Posisi penjalaran retak pada Spesimen D1

Pada Gambar 10 terlihat bahwa retak muncul dan menjalar pada pencekaman bagian bawah. Hal ini menandakan pemberian pengaku dan lasan pada daerah retakan cukup baik untuk menghambat laju retakan pada daerah retakan awal yang diberikan.

Perbandingan nilai rata-rata beban kritis untuk variasi spesimen pengujian diperlihatkan pada gambar 11. Pada gambar terlihat penggunaan pengaku satu sisi dengan lebar $20 \mathrm{~mm}$ (Spesimen D) sangat efektif dalam menghambat laju rambatan retak. Hal ini terlihat dari nilai rata-rata beban kritisnya tertinggi,sedangkan metode penghambat retakan dengan lasan saja (Spesimen B) kurang efektif dalam menghambat penjalaran retak, akan tetapi metode penghambatan retak dengan lasan saja masih dapat menghambat laju rambatan retak. Hal ni terlihat dari nilai beban kritisnya masih lebih tinggi dari spesimen yang diberi retakan awal (Spesimen A).

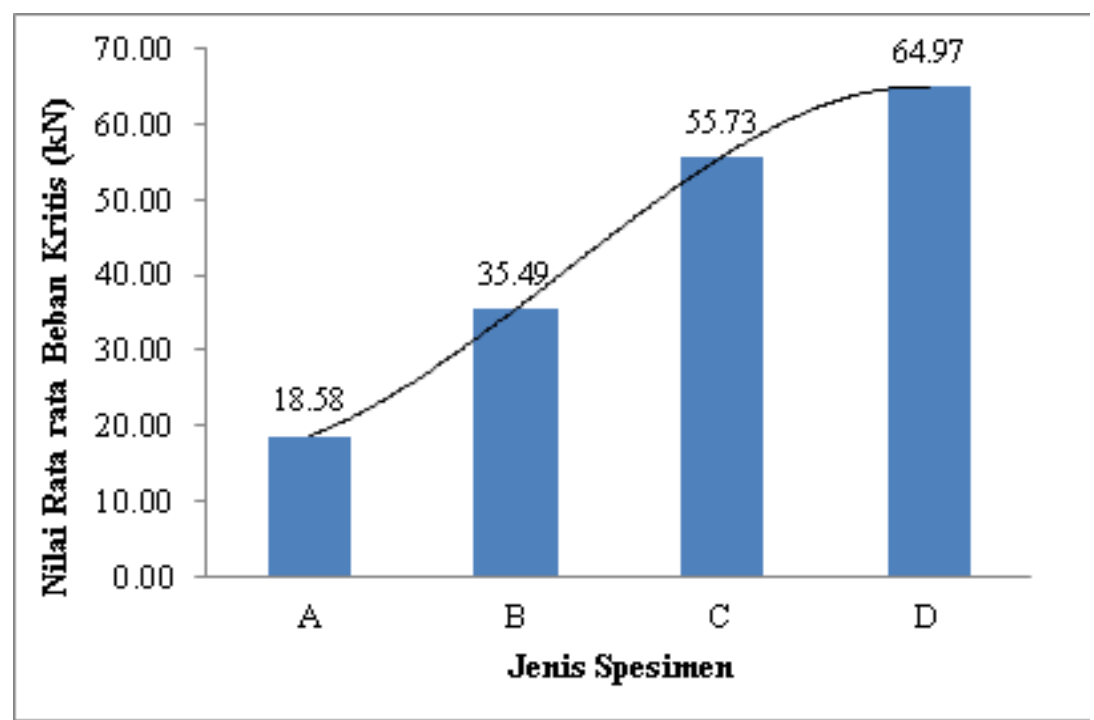

Gambar 11. Perbandingan nilai rata-rata beban kritis untuk variasi Jenis Spesimen 


\section{KESIMPULAN}

Dari penelitian yang telah dilakukan dapat disimpulkan bahwa:

1. Pengaku yang diberikan sangat mempengaruhi laju perambatan retak di mana penggunaannyasangat efektif dalam meningkatkan nilai beban kritis sebelum retak menjalar.

2. Dimensi pengaku mempengaruhi penghambatan penjalaran retak di mana semakin besar dimensi pengaku maka rata rata beban kritis yang dibutuhkan untuk retak mulai menjalar semakin besar.

3. Metode lasan pada retak dapat menghambat penjalaran retak meskipun kurang efektif dibandingkan dengan metode lainnya

4. Pengelasan yang kurang baik akan menyebabkan pertumbuhan retak dimulai pada daerah tersebut sehingga nilai beban kritis menjadi rendah.

\section{Ucapan Terimakasih.}

Peneliti mengucapkan terimakasih kepada Jurusan Teknik Mesin Universitas Andalas atas dana yang diberikan untuk penelitian ini dengan surat kontrak perjanjian pelakasanaan penugasan kegiatan penelitian dosen dengan nomor kontrak 072/UN.16.09.D/PL/2017.

\section{DAFTAR PUSTAKA}

[1] Murdani A., Macabe C., Saimoto A., Kondo R. 2008. A Crack Growth Arresting Technique in Aluminum Alloy. Engineering Failure Analysis 15 (2008) 302-310.

[2] Macabe C., Murdani A., Kuniyoshi K., Irei Y., Saimoto A. 2009. Crack - Growth Arrest by Redirecting Crack Growth by Drilling Stop Holes and Inserting Pins into Them. Engineering Failure Analysis 16 (2009) 247-483.

[3] Marazani T., Madyira D. M.,Akinlabi E. T. 2017. Repair of cracks in metals: A review. 14th Global Conference on Sustainable Manufacturing, GCSM 3-5 October 2016, Stellenbosch, South AfricaProcedia Manufacturing 8 (2017) 673-679

[4] Macabe C., Naka K., Ferdous M. S. 2014. Method of Arresting Crack Growth for Application at Narrow Working Space. Bulletin of the JSME, Mechanical Engineering Journal Vol.1 No.6.

[5] Macabe C., Naka K., Katshusima Y. 2015. Example of Arresting Crack Growth in Welded Parts. Indutrial Engineering and Management Vol.4 issue.5.

[6] Nateche T., Meliani M.H., Matvienko Y.G., Pluvinage G. 2016. Drilling Repair Index (DRI) Based on Two-parameter Fracture Mechanics for Crack Arrest Holes. Engneering Failure Analysis 59 (2016) 99 - 110. 